Elek, S. D., Hilson, G. R. F. \& Jewell, P. (1953). Brit. med. F. ii, 1298.

Gardner, K. E., Nevens, W. B., Folkerts, T. \& Johnson, B. C. (1952). F. Anim. Sci. II, 76I.

Gordon, H. A. (1952). In $A$ Colloquium 'Studies on the Growth Effect of Antibiotics in Germ-free Animals'. Notre Dame, Indiana: Lobund Institute, University of Notre Dame (Mimeo.).

Gunnison, J. B., Coleman, V. R. \& Jawetz, E. (1950). Proc. Soc. exp. Biol., N. Y., 75, 549.

Gunnison, J. B., Jawetz, E. \& Coleman, V. R. (1950). F. Lab. clin. Med. 36, goo.

Hunter, J. H. (1950). F. Amer. med. Ass. 144, 524.

Ingram, P. L., Lovell, R., Wood, P. C., Aschaffenburg, R., Bartlett, S., Kon, S. K., Palmer, J., Roy, J. H. B. \& Shillam, K. W. G. (1956). F. Path. Bact. 72, $56 \mathrm{r}$.

Jawetz, E., Gunnison, J. B., Bruff, J. B. \& Coleman, V. R. (1952). F. Bact. 64, 29.

Kastelic, J., Bentley, O. G. \& Phillips, P. H. (1950). F. Dairy Sci. 33, 725.

Knodt, C. B. \& Bloom, S. (1952). F. Dairy Sci. 35, 675.

Kon, S. K., Oliver, J., Porter, J. W. G. \& Ridler, B. (1953). Proc. Nutr. Soc. 12, x.

Lassiter, C. A. (1955). F. Dairy Sci. 38, I I02.

Pepper, W. F., Slinger, S. J. \& Motzok, I. (1953). Poult. Sci. 32, 656.

Roy, J. H. B., Palmer, J., Shillam, K. W. G., Ingram, P. L. \& Wood, P. C. (1955). Brit. F. Nutr. 9, I I.

Roy, J. H. B., Shillam, K. W. G., Palmer, J. \& Ingram, P. L. (1955). Brit. F. Nutr. 9, 94.

Rusoff, L. L., Landagora, F. T. \& Hester, H. H. (1954). F. Dairy Sci. 37, 654 .

Smith, H. W. (1954). Vet. Rec. 66, 42.

Smith, H. W. \& Crabb, W. E. (1956a). Vet. Rec. 68, 274.

Smith, H. W. \& Crabb, W. E. (1956b). F. gen. Microbiol. 15, 556.

Taylor, J. H. (1955). The effect of adding an antibiotic supplement to the diet of animals with special reference to the mode and site of action. Ph.D. Thesis, University of Reading.

Taylor, J. H. \& Harrington, G. (1955). Nature, Lond., 175, 643 .

Voelker, H. \& Jacobson, N. L. (1953). F. Dairy Sci. 36, 592.

Wood, P. C. (1955). F. Path. Bact. 70, 179.

\title{
Flour and bread, prepared with or without treatment with chlorine dioxide, as long-term sources of vitamin $E$ for rats
}

\author{
BY T. MOORE, I. M. SHARMAN AND R. J. WARD \\ Dunn Nutritional Laboratory, University of Cambridge and Medical Research Council
}

(Received 7 Fanuary 1958)

The destruction of vitamin $\mathrm{E}$ in flour by chlorine dioxide was first reported by Moran, Pace \& McDermott (1953). Chemical estimations of total tocopherols indicated a loss of $70 \%$ after the application of the improver at the rate of 30 p.p.m., which was the commercial level current at the time of their experiments. Later the same authors (Moran et al. 1954) mentioned similar experiments in which a loss of $95 \%$ of the total reducing substances in the unsaponifiable matter of the wheat oil was observed. According to chemical estimations by Frazer, Hickman, Sammons \& Sharratt (1956), flour of $78 \%$ extraction rate contained I. $5 \mathrm{mg} \alpha$-tocopherol $/ \mathrm{r} 00 \mathrm{~g}$, which was reduced to $0.2 \mathrm{mg}$ after treatment with chlorine dioxide at the normal level. Their value for the untreated flour was about three times higher than would be expected, in our experience, for flour of $80 \%$ extraction rate. The destruction of the vitamin by chlorine dioxide was confirmed in biological tests on rats, which had smaller testes when their diet had contained bread crumbs made from $\mathrm{ClO}_{2}$-treated flour than when the crumbs had been made from untreated flour. 
In our own studies (Moore, Sharman \& Ward, I957a) a specimen of untreated flour, of $80 \%$ extraction, was found by chemical methods to contain $1.57 \mathrm{mg}$ total tocopherols $/ 100 \mathrm{~g}$, with $0.35 \mathrm{mg}$ in the $\alpha$-form. After treatment with chlorine dioxide, 30 p.p.m., these levels fell to 0.19 and $0.04 \mathrm{mg}$, respectively. In agreement with these findings, untreated flour proved an adequate source of vitamin $\mathrm{E}$ for rats when it was supplied to them as the main component of their diet. Flour treated with chlorine dioxide did not prevent the development of avitaminosis E, as demonstrated by several criteria. In a preliminary trial, moreover, it was found that sufficient vitamin $E$ to supply the needs of rats survived in bread baked from untreated flour, as judged solely by the haemolysis test with dialuric acid (György \& Rose, 1949). As expected, bread baked from flour treated with chlorine dioxide was inadequate, judged in the same way.

We have now to describe: (I) a further trial of untreated and $\mathrm{ClO}_{2}$-treated flours as sources of vitamin $E$ when given to rats over unusually long periods, (2) the completion, with the application of several methods for examining the vitamin $\mathrm{E}$ status, of the experiment on rats fed upon bread made from treated and untreated flour, from which preliminary haemolysis tests have already been recorded (Moore et al. 1957a). Both these investigations have been summarized in a preliminary communication (Moore et al., 1957b).

\section{EXPERIMENTAL}

Experiment $\mathrm{I}$ on flour. Twenty female albino rats, of body-weight $4{ }^{1-62} \mathrm{~g}$ were divided into two equal groups, with as even distribution as possible of the same weights between groups. They were given a diet made of flour (untreated or $\mathrm{ClO}_{2}$ treated) 85.5 , casein 5 , lard 8 , dried yeast 8 and minerals 4 parts. Vitamin A was supplied as 1000 i.u. of vitamin A acetate, vitamin D as Radiostol (British Drug Houses Ltd) in a dose supplying 60 i.u. calciferol, and vitamin $\mathrm{K}$ as $5^{\circ} \mu \mathrm{g}$ 2-methylI :4-naphthoquinone, all weekly. This weekly dose of each vitamin was diluted in $20 \mathrm{mg}$ arachis oil.

Experiment 2 on bread. Chalk was added to portions of flour used in Exp. I at a level of $3 \cdot \mathrm{Ig} / \mathrm{kg}$, as laid down by the Regulations for the fortification of flour in Great Britain (Great Britain. Parliament, I953). Dough was made from I oz. $(28 \cdot 3 \mathrm{~g})$ yeast and approximately $20 \mathrm{oz} .(567 \mathrm{~g})$ flour, which gave loaves weighing approximately $30 \mathrm{oz} .(85 \circ \mathrm{g})$ after baking. Loaves were made by a local baker three times weekly. Eighteen male albino rats, of body-weight 82-121 g, were divided into two equal matched groups $\left(\mathrm{ClO}_{2}\right.$ and untreated groups). Their diet consisted entirely of bread, supplemented only with one $20 \mathrm{mg}$ drop of halibut-liver oil weekly to make good the well-known inadequacy of bread in vitamins $\mathrm{A}$ and $\mathrm{D}$. The dose supplied I000 i.u. vitamin A.

Flour. It was kindly supplied by the Cereals Research Station of the Research Association of British Flour-Millers. Stocks of $80 \%$ extraction wheat flour were kept at St Albans, where each week the required quantity was treated with chlorine dioxide, at the level of $3 \circ$ p.p.m. This flour, and the same amount untreated, was sent 
to Cambridge for the feeding trials. Weekly checks indicated that the yellow colour due to flour lipids was regularly reduced to about one-tenth of its original value by the treatment with chlorine dioxide.

Haemolysis tests. Tests made on each animal (Moore et al. 1957a) were based on that of György \& Rose (1949). Erythrocytes, obtained from the tails of the rats, were subjected to the action of dialuric acid in a buffer solution. The degree of haemolysis was then estimated from the red colour remaining after the removal of any intact erythrocytes by centrifugation.

Dental pigmentation. The front surfaces of the upper incisors of all the rats were inspected weekly, and their final colour at the end of the experiment was recorded.

Paralysis. The movements of the animals in their cages were observed throughout the experiments. In addition, a final test of walking powers on a smooth surface was made shortly before the end of each experiment. The degrees of paralysis that came under observation were arbitrarily graded into five stages: stage I, slight abnormality in gait; stage 2 , decided abnormality in gait; stage 3 , hind-legs turned outwards, and movement with difficulty during walking. Further stages, finishing at stage 5 with complete paralysis of the hind-legs, were not observed in the present experiments.

Skin lesions. The animals were inspected regularly for the appearance of skin sores, which were first reported as an effect of vitamin $\mathrm{E}$ deficiency by Martin \& Moore (I939).

Brown uterus. At autopsy the colour of the uterus was recorded according to an arbitrary grading: stage $\mathbf{I}$, barely perceptible brown discoloration in ordinary light, with yellow-brown fluorescence under ultraviolet irradiation as confirmation (Moore $\&$ Wang, 1947); stage 2, pale but unequivocal brown colour in ordinary light; stage 3 , medium brown, or buff; stage 4 , chestnut or dark brown.

Degeneration of the testes. At autopsy the testes were dissected out and weighed promptly. They were then fixed in formol-saline for the preparation of paraffin sections, which were stained with haematoxylin and eosin.

Kidney autolysis. The kidney abnormalities observed in vitamin E-deficient rats by Martin \& Moore (1939) have been shown to be developed, at least as seen in paraffin sections, by the action of post-mortem autolysis (Emmel, 1957; Moore, Sharman \& Symonds, 1958). In the present work, therefore, the kidneys were dissected out and placed in fixative after the carcasses had been kept, at room temperature, for exactly $3 \mathrm{~h}$ after death. Otherwise the sections were prepared as for the testes.

Estimation of vitamin A. Moore (1940) found that the vitamin A reserves of rats that had been subjected to prolonged vitamin $E$ deficiency were much lower than those of rats that had received vitamin E. For our extraction of the vitamin the method of Davies (I933), involving digestion of the liver tissues with alkali, was employed. The blue colour in the antimony-trichloride reaction was measured in a home-made photoelectric absorptiometer. 
RESULTS

\section{Experiment $\mathrm{x}$ on flour}

Effects of flour diets as observed during life. Growth curves are shown in Fig. I. The mean body-weights almost coincided for the first ito days of the experiment, but subsequently the mean for the rats receiving untreated flour was slightly higher than that for those receiving treated flour. Thus after 376 days the mean weight increase of the rats on the untreated-flour diet was $190 \mathrm{~g}$ and of those on the treated-flour diet I $54 \mathrm{~g}(P<0.01)$. The difference in body-weights was presumably due mainly to the extent of the fat deposits in the two groups (see below).

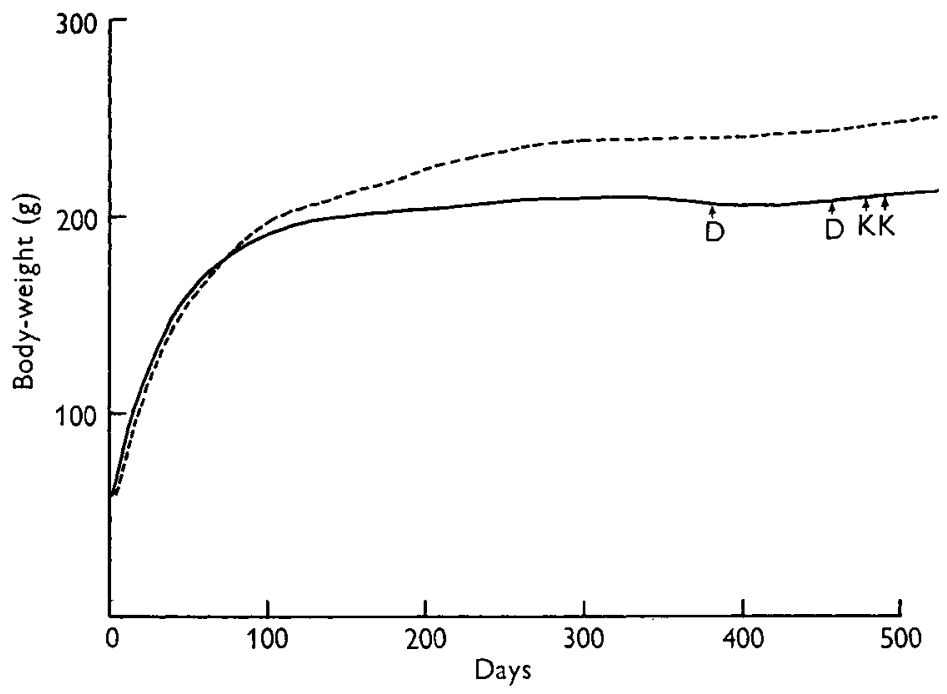

Fig. I. Exp. I. Growth curves of rats fed on diets with untreated, - - , and $\mathrm{ClO}_{2}$-treated, —, flour. $\mathrm{D}$, died; $\mathrm{K}$, killed.

Dental depigmentation occurred uniformly in all the rats of the $\mathrm{ClO}_{2}$ group. In both groups the incisors developed their brown colour normally during the first few weeks of the experiment. In the $\mathrm{ClO}_{2}$ group, however, the colour of the upper incisors was lost within 40-96 days of the beginning of the experiment, and the depigmentation persisted until its end.

Skin sores, of the type characterizing chronic avitaminosis $\mathrm{E}$ in the rat, were observed in all but one of the animals given $\mathrm{ClO}_{2}$-treated flour. The most frequent site of the sores was the base of the tail (Pl. I, I), but sometimes the flanks, abdomen or neck were affected. No sores due to vitamin E deficiency were observed in the group given untreated flour. Contrary to our general experience, the sores of two of the rats (Table I, rats nos. 7 and 8 ) reached their maximum severity after $470-480$ days and then regressed. At the conclusion of the experiment these two animals were virtually free from sores.

Haemolysis tests were applied on day 509 of the experiment to all the surviving rats 
in each group. The percentage of haemolysis in the group given untreated flour was 0 for each of the ten animals. For the group given $\mathrm{ClO}_{2}$-treated flour the mean haemolysis was $92 \%$.

Tests for paralysis were also applied on day 509. Early signs were observed in all the animals that had received $\mathrm{ClO}_{2}$-treated flour: there was no evidence of paralysis in the group given untreated flour.

Effects of flour diets as observed post mortem. Of the rats given $\mathrm{ClO}_{2}$-treated flour two died before the end of the experiment, and two others were killed in weak condition. The findings at autopsy are given in Table $\mathrm{I}$.

Table 1. List of rats dying or killed before the intended end of the experiment, with post-mortem findings

\begin{tabular}{|c|c|c|c|c|c|}
\hline Exp. no. & $\begin{array}{l}\text { Treatment } \\
\text { of flour }\end{array}$ & $\begin{array}{l}\text { Rat } \\
\text { no. }\end{array}$ & $\begin{array}{l}\text { Day of } \\
\text { death }\end{array}$ & $\begin{array}{l}\text { Killed or } \\
\text { died }\end{array}$ & Post-mortem findings \\
\hline I & $\mathrm{ClO}_{2}$ & 2 & $3^{8} 3$ & D & $\begin{array}{l}\text { Emaciated; large open sore in pubic } \\
\text { area and around base of tail }\end{array}$ \\
\hline I & $\mathrm{ClO}_{2}$ & 6 & 469 & $\mathrm{D}$ & $\begin{array}{l}\text { Emaciated; sores at base of tail, left } \\
\text { thigh, throat and front legs; anaemic }\end{array}$ \\
\hline I & $\mathrm{ClO}_{2}$ & I & 484 & $\mathrm{~K}$ & $\begin{array}{l}\text { Emaciated; sores at base of tail; septic } \\
\text { uterus; enlarged spleen }\end{array}$ \\
\hline $\mathbf{I}$ & $\mathrm{ClO}_{2}$ & 5 & 488 & $\mathrm{~K}$ & $\begin{array}{l}\text { Emaciated; sores on shoulders and at } \\
\text { base of tail; septic uterus; enlarged } \\
\text { spleen }\end{array}$ \\
\hline 2 & None & 2 & 372 & $\mathrm{~K}$ & $\begin{array}{l}\text { Killed while moribund; bleeding around } \\
\text { nose; not emaciated, but stomach } \\
\text { empty; cause of illness obscure }\end{array}$ \\
\hline 2 & $\mathrm{ClO}_{2}$ & 3 & 314 & $\mathrm{D}$ & Emaciated; enteritis \\
\hline
\end{tabular}

On day 5 Io the six surviving rats in the group given $\mathrm{ClO}_{2}$-treated flour were killed, as also were six animals taken at random from those given untreated flour.

Brown discoloration of the uterus had reached an advanced stage in all the animals given $\mathrm{ClO}_{2}$-treated flour. In all the animals given untreated flour the uterus was normal in colour.

Vitamin A estimations indicated a mean total reserve of 5000 i.u. in the group given $\mathrm{ClO}_{2}$-treated flour, compared with $19,000 \mathrm{i} . \mathrm{u}$. in the group given untreated flour.

Kidney degeneration, as indicated by post-mortem autolysis, was severe in all the animals given $\mathrm{ClO}_{2}$-treated flour. In the group given untreated flour there was no degeneration (Pl. I, 2,3).

Deposits of adipose tissue were compared by dissecting out the intraperitoneal-fat deposits. Weighings averaged $\mathrm{r} \cdot 3 \mathrm{~g}$ for the animals given $\mathrm{ClO}_{2}$-treated flour, as against $14.4 \mathrm{~g}$ for the animals given untreated flour. The combined findings in Exp. I, before and after the deaths of the animals, are summarized in Table 2.

\section{Experiment 2 on bread}

Effects of bread diet during life. Average growth curves are shown in Fig. 2. With bread from either $\mathrm{ClO}_{2}$-treated or untreated flour the animals grew better than might perhaps have been expected. Body-weights approaching the normal maximum were 


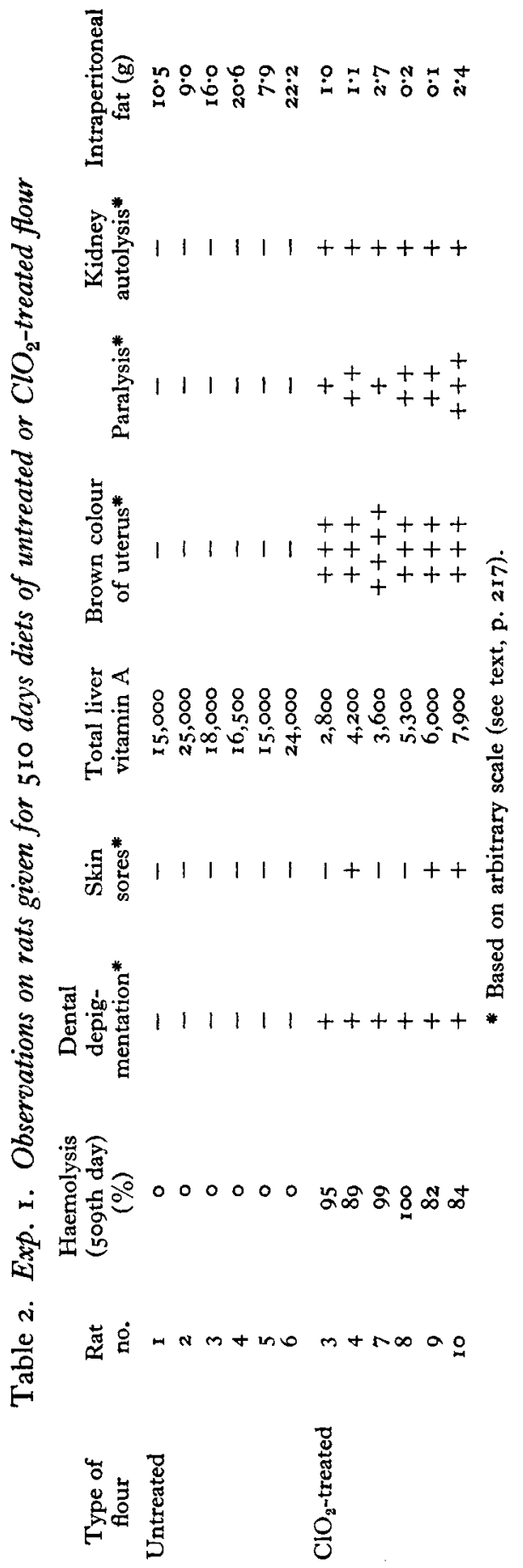


eventually reached, although much less rapidly than would in our experience have been expected with a good mixed diet.

The animals on the bread made from untreated flour at first grew more rapidly than those on bread made from $\mathrm{ClO}_{2}$-treated flour. Thus, after 45 days the mean increase in the weight of the untreated group was $114 \mathrm{~g}$ and of the treated group $99 \mathrm{~g}$ $(0.05<P<0 . \mathrm{I})$. As the experiment proceeded, however, the differences between the increases in weight of the animals in the two groups decreased. Although at the end of the experiment the mean weight increase of the animals in the treated group seemed slightly lower $\left(223^{\cdot}\right)$ than of those in the untreated group $(242 \cdot 5)$, the difference was not significant $(0 \cdot 2<P<0 \cdot 3)$.

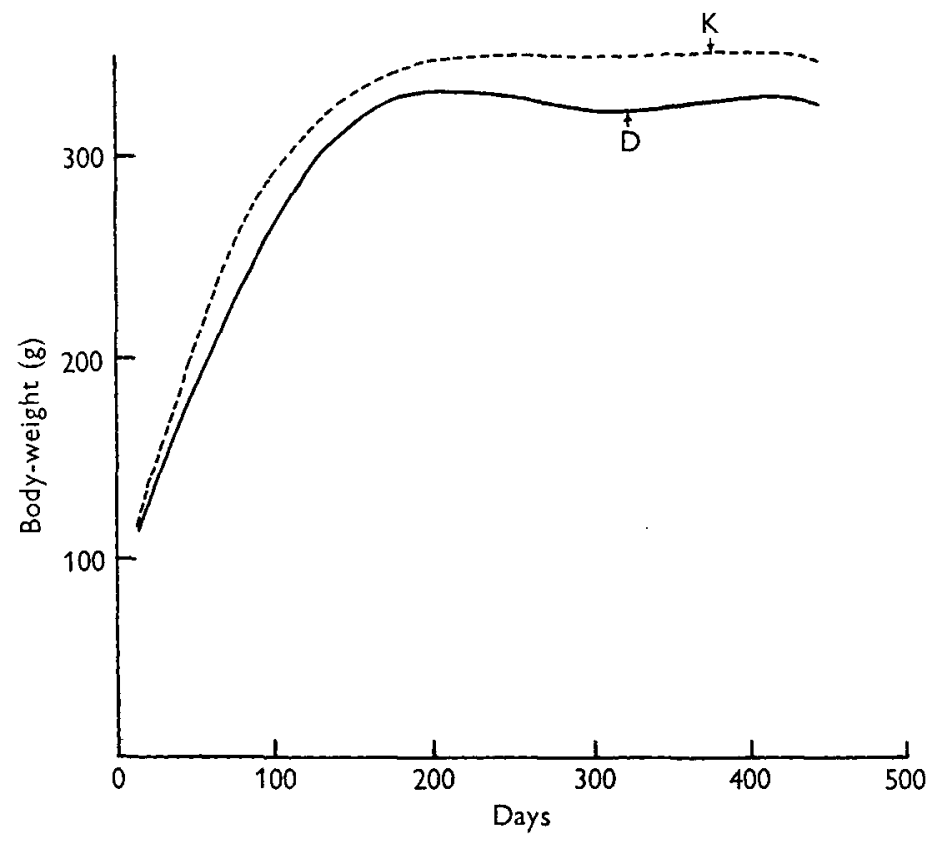

Fig. 2. Exp. 2. Growth curves of rats fed on bread made from $\mathrm{ClO}_{2}$-treated, and untreated, - - , flour. $D$, died; $K$, killed.

Dental depigmentation was observed, with one exception, in all the rats in the $\mathrm{ClO}_{2}$ group. The loss of brown colour, however, was sometimes less complete than in Exp. $\mathrm{x}$. Thus in some of the teeth faint brown mottling appeared on a white background. In the rats given bread made from untreated flour pigmentation was normal.

Skin sores, of the type characteristic of vitamin E, were not observed during this experiment. In both groups, however, some of the animals suffered from 'pressure pads' on their hind-legs, which usually developed into open sores. These sores are not characteristic of avitaminosis $\mathrm{E}$.

Paralysis, in contrast to our findings in Exp. r, could be observed with certainty in neither group. In some of the animals walking tests were difficult to interpret, because of ankylosis of the joints underlying the pressure pads. In the later stages of the experiment the animals of both groups seemed unwilling to be handled. 
Haemolysis tests were first applied on day 59. In the $\mathrm{ClO}_{2}$ group haemolysis averaged $85.7 \%$, compared with $4.7 \%$ in the untreated group. In further tests on day 440 the means were 99.3 and $\mathrm{I} \cdot \mathrm{I} \%$.

Effects of bread diets as observed post mortem. Before the end of the experiment one rat in each group died or was killed when moribund. The findings at autopsy are given in Table $\mathrm{I}$.

On day 44I six animals from each group were killed. The testes were dissected and weighed. They were found invariably to be much smaller in the $\mathrm{ClO}_{2}$ group, with a mean of $\mathrm{r} \cdot 33 \mathrm{~g}$, than in the untreated group, with a mean of $3.2 \mathrm{~g}$. The degeneration of the testes in the $\mathrm{ClO}_{2}$ group was confirmed histologically.

Vitamin A estimations indicated mean total reserves of 2 roo i.u. in the $\mathrm{ClO}_{2}$ group, compared with 13,000 i.u. in the untreated group.

Kidney degeneration in the severe form observed in Exp. I was observed in neither group. At the most a few areas of degeneration were found in kidneys of rats from the $\mathrm{ClO}_{2}$ group.

The combined findings in Exp. 2 are summarized in Table 3.

\section{DISCUSSION}

Chemical estimations (Moran et al. 1953, 1954; Frazer et al. 1956; Moore et al. $1957 a, b)$ have left no doubt about the real destruction by chlorine dioxide of vitamin $\mathrm{E}$ in flour. Uncertainty remains, however, over the practical importance of this finding. In some quarters there has been a tendency to regard vitamin $\mathrm{E}$ as being concerned only with sexual functions (e.g. Anonymous, 1957). Since reproduction is often normal in human subjects, it is thought either that they do not need vitamin E, or that their supplies are already adequate, in spite of the use of destructive flour improvers. Another contention is that flour could provide only a small fraction of the normal human intake of vitamin $\mathrm{E}$, even if chlorine dioxide were not used. Finally there is evidence that losses of vitamin $\mathrm{E}$ in untreated flour occur during storage, and particularly during the baking of bread. It seems fruitless to be unduly concerned about the destruction of vitamin $\mathrm{E}$ by chlorine dioxide, therefore, if much of it is inevitably lost through other causes.

The force of these arguments, except for that associating the action of vitamin $\mathrm{E}$ exclusively with reproduction, must not be unduly minimized. We must realize, however, that there is still room for improvement in our methods for estimating the vitamin and in our knowledge about the amounts of it contributed by different foods. It seems possible, for example, that the apparent loss of vitamin $\mathrm{E}$ during baking may be due, at least in part, to the much greater difficulty of extracting lipids from bread than from flour (Cookson \& Coppock, I956). Uncertainty also arises from variations in the composition of margarine and cooking fats. These foods can provide a predominant fraction of our vitamin $E$ intake if they are made from certain vegetable oils, but much less if they are made from other oils (Ward, 1958). The importance of the balance between unsaturated fats and vitamin E, moreover, must be taken into account (Dam, 1955). In assessing the potency of various sources of vitamin $\mathrm{E}$ it may be necessary 
Vol. I2

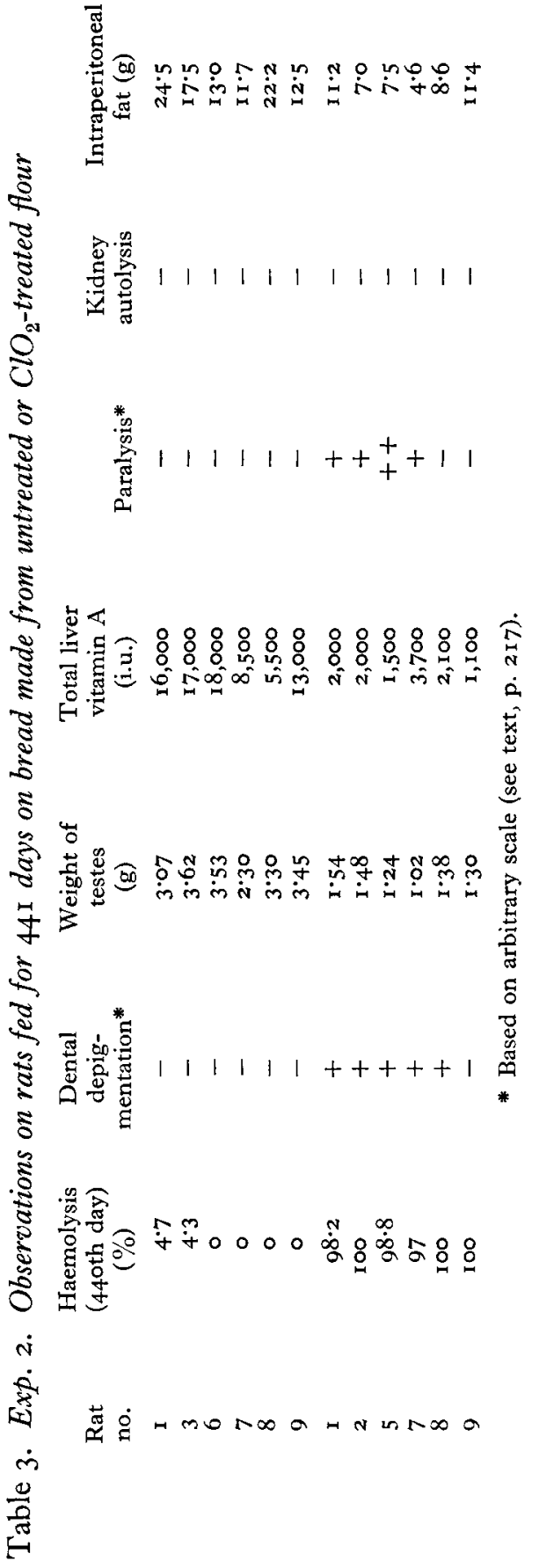

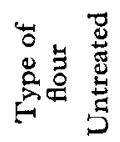

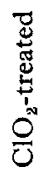


not only to give credit for the amounts of the various tocopherols present, but also to make a deduction according to the strain placed on vitamin $\mathrm{E}$ metabolism by the accompanying fats. This problem, indeed, has already been considered in relation to cod-liver oil (Moore et al. I956).

The results of the present experiments must leave open the question of the possible value of flour as a source of vitamin $E$ for human beings. It is clear, however, that untreated flour of $80 \%$ extraction rate, or bread baked from it, proved, when supplied as the main component of the diet, an adequate source of vitamin $\mathrm{E}$ for rats. The activity was demonstrated in various animals by the prevention, over long periods, of lesions both in the sex organs and the rest of the body. The lesions prevented, all characteristic of avitaminosis $\mathrm{E}$, included defective resistance to haemolysis, dental depigmentation, reduced storage of vitamin $A$ and degeneration of the testes or brown uterus. Flour that had been treated with chlorine dioxide, or bread baked from it, was ineffective in preventing these lesions.

In female rats, used in Exp. I, the untreated flour was also effective against the incipient paralysis and the skin sores that appeared in the animals given $\mathrm{ClO}_{2}$-treated flour. Degeneration of the kidneys, as indicated by post-mortem autolysis, was prevented by the untreated flour. None of these abnormalities were observed in the male rats used in Exp. 2, even in the group given bread made from $\mathrm{ClO}_{2}$-treated flour. In our previous experience (Moore et al. 1955) male rats were less liable to paralysis than females. Our failure to observe autolysis in the kidneys of rats fed on bread made from $\mathrm{ClO}_{2}$-treated flour may readily be explained by the role of the dietary fat in predisposing towards this lesion (Moore et al. 1956). A diet consisting only of bread presumably contains too little unsaturated fat to cause kidney autolysis, even in the absence of vitamin $\mathrm{E}$.

For the development of the skin lesions typical of vitamin $\mathrm{E}$ deficiency we cannot exclude the intervention of mites, which are difficult to control in rats kept in captivity for long periods. This matter is under investigation, but our experience indicates clearly that rats adequately supplied with vitamin E do not develop open sores, even when heavily infested with mites. The foot sores, observed in the second experiment, which are also under investigation, are not related to the vitamin $\mathrm{E}$ status.

Frazer et al. (1956) have reported that bread crumbs made from untreated flour, but not those from $\mathrm{ClO}_{2}$-treated flour, are adequate as a source of vitamin $\mathrm{E}$ for rats. This conclusion, based on a short-term experiment and with the size and condition of the testes as a criterion, is substantially in agreement with the results of our work. It seems fair to state that untreated flour, or bread made from it, provides at least its fair share of the total daily vitamin $\mathrm{E}$ requirement. With $\mathrm{ClO}_{2}$-treated flour, however, the need for supplying the corresponding amount of vitamin $\mathrm{E}$ is thrown upon other foodstuffs.

A remarkable feature of vitamin $\mathrm{E}$ deficiency in the adult rat, clearly indicated by our experiments, is the long period of survival after the first signs of deficiency have been displayed. The appearance of dental depigmentation indicated that our animals became deficient in the vitamin within a few weeks of the beginning of the experiment. In other work we have found that the haemolysis test often became positive within a 
few days of restriction to a deficient diet. Many of our animals, therefore, survived for nearly 18 months in a state of chronic deficiency. It seems reasonable to assume that sooner or later during this period they would have proved unduly sensitive, if tested, to various stresses, including injections of alloxan (György \& Rose, I949) or vitamin $K$ substitutes (Allison, Moore \& Sharman, 1956), and hyperoxia (Taylor, 1953).

\section{SUMMARY}

I. Female rats were taken at weaning, and were given for 17 months a diet which consisted mainly of flour, of $80 \%$ extraction rate, but which also included casein, lard and dried yeast. In another experiment male rats were taken when slightly older, and were kept for 15 months on bread baked from the same flour, with the addition only of chalk and live yeast. In both experiments supplements of vitamins A and D were allowed.

2. No evidence of vitamin $\mathrm{E}$ deficiency was found in either experiment, provided that the flour had not been subjected to chemical treatment.

3. Flour treated with chlorine dioxide, at about the usual commercial level, or bread baked from it, was ineffective as a source of vitamin $\mathrm{E}$. The lesions developed included brown discoloration of the uterus, degeneration of the testes, dental depigmentation, haemolysis in vitro by dialuric acid and the defective storage of vitamin $A$. With the flour diet, which contained lard, but not with bread, additional effects of avitaminosis $\mathrm{E}$ were observed in the form of incipient paralysis, skin sores and postmortem autolysis in the kidneys.

4. We may therefore infer that untreated flour, or bread baked from it, provides at least its fair share of the total vitamin $\mathrm{E}$ requirement. The use of chlorine dioxide involves supplying the vitamin from other foodstuffs.

This work was undertaken as part of a programme, in collaboration with Dr L. J. Harris, on the effect of improvers on the nutritive value of flour. We thank him for his interest and criticism. We are also grateful to the Research Association of British Flour-Millers, and particularly to Dr J. Pace, for preparing the flour specimens. Mr E. Webb kindly undertook the baking of loaves. We acknowledge gratefully the technical assistance of Mrs P. J. Richards, Miss Margaret Anable and Mr Brian Wayman.

\section{REFERENCES}

Allison, A. C., Moore, T. \& Sharman, I. M. (1956). Brit. F. Haematol. 2, 197.

Anonymous (1957). Milling, p. 426.

Cookson, M. A. \& Coppock, J. B. M. (1956). F. Sci. Fd Agric. 7, 72.

Dam, H. (1955). Progr. Chem. Fats Lipids, 3, 155.

Davies, A. W. (1933). Biochem. F. 27, 1770.

Emmel, V. M. (1957). F. Nutr. 61, 5 I.

Frazer, A. C., Hickman, J. R., Sammons, H. G. \& Sharratt, M. (1956). F. Sci. Fd Agric. 7, 375.

Great Britain. Parliament (1953). The Flour Order, 1953. Stat. Instrum. no. 1282.

György, P. \& Rose, C. S. (I949). Ann. N.Y. Acad. Sci. 52, 23 I.

Martin, A. J. P. \& Moore, T. (1939). F. Hyg., Camb., 39, 643.

Moore, T. (1940). Biochem. F. 34, I32r.

Moore, T., Sharman, I. M. \& Symonds, K. R. (1958). Proc. Nutr. Soc. 17, vi. 
Moore, T., Sharman, I. M. \& Ward, R. J. (1955). Congr. int. Biochim. III. Brussels. Résumés des Communications, p. II 4 .

Moore, T., Sharman, I. M. \& Ward, R. J. (1956). Biochem. F. 64, 13P.

Moore, T., Sharman, I. M. \& Ward, R. J. (1957a). F. Sci. Fd Agric. 8, 97.

Moore, T., Sharman, I. M. \& Ward, R. J. (1957b). Proc. Nutr. Soc. 16, xix.

Moore, T. \& Wang, Y. L. (1947). Brit. F. Nutr. I, 53.

Moran, T., Pace, J. \& McDermott, E. E. (1953). Nature, Lond., r71, 103.

Moran, T., Pace, J. \& McDermott, E. E. (1954). Nature, Lond., r74, 449.

Taylor, D. W. (1953). F. Physiol. 121, 47 P.

Ward, R. J. (1958). Brit. F. Nutr. 12, 23 I.

\title{
EXPLANATION OF PLATE
}

1. Skin sore, characteristic of prolonged deficiency of vitamin E, observed in a rat (rat no. I, Table I) fed for 484 days on a diet containing flour treated with chlorine dioxide.

2. 'Typical photomicrograph of the kidney cortex of a rat receiving the diet containing untreated flour for 5 10 days (rat no. 6, Table 2). Kidney fixed $3 \mathrm{~h}$ after death. Note virtual absence of autolysis in the tubules.

3. Typical photomicrograph of the kidney cortex of a rat (rat no. 9, Table 2) receiving the diet containing $\mathrm{ClO}_{2}$-treated flour for 5 ro days. Kidney fixed $3 \mathrm{~h}$ after death. Note extensive autolysis in the tubules.

\section{The biological activities of $\epsilon$ - and $\zeta$-tocopherols}

\author{
BY R. J. WARD
}

Dunn Nutritional Laboratory, University of Cambridge and Medical Research Council

(Received 7 Fanuary 1957)

Assessment of vitamin E potency of untreated flour, and of bread baked from it without the use of destructive improvers, has been complicated by the presence of $\epsilon$-tocopherol (5-monomethyl tocol) and $\zeta$-tocopherol (5:7-dimethyl tocol). The same problem arises over British margarine, which also contains these tocopherols. According to analyses carried out in this laboratory, flour of $80 \%$ extraction contains about $23 \%$ of $\alpha-, 16 \%$ of $\beta-, 5 \%$ of $\zeta$ - and $56 \%$ of $\epsilon$-tocopherol, with a total tocopherol content of $x \cdot 82 \mathrm{mg} / \mathrm{I} 00 \mathrm{~g}$ dry weight (Moore, Sharman \& Ward, I957). Palm oil is used in the manufacture of British margarine and contains about $50 \% \alpha-, 34 \% \zeta-$ and $16 \% \eta$-tocopherol, with a total tocopherol content of $32.7 \mathrm{mg} / \mathrm{100} \mathrm{g}$ (Ward, $195^{8}$ ). $\epsilon-$ and $\zeta$-tocopherols are also present in the rations of farm animals, particularly in those containing barley meal or wheat middlings.

In order to estimate the vitamin $\mathrm{E}$ activity of any food, it is necessary to have a knowledge of both the relative biological activities and the individual amounts of the various forms of tocopherol present. Although $\epsilon$-tocopherol has been synthesized (Karrer \& Dutta, I948), there is no published information about its biological activity. It has been suggested by Eggitt \& Norris ( $\left.195^{6}\right)$, however, that from its chemical constitution it should have the activity of $\beta$-tocopherol or about $30 \%$ of that of $\alpha$-tocopherol. $\zeta$-Tocopherol was synthesized nearly 20 years ago by Karrer $\&$ Fritsche 